\title{
Ileo-colonic infiltration in acute myeloid leukemia
}

A 66-year-old woman with diffuse, persistent colicky abdominal pain for the past 2 months with postprandial abdominal distension, weight loss ( $3 \mathrm{~kg}$ ), asthenia, anorexia, and sporadic vomiting attended the emergency room. Blood investigations revealed hemoglobin $11.6 \mathrm{~g} / \mathrm{dL}$, platelets $82 \times 10^{9} / \mathrm{L}$, C-reactive protein $135 \mathrm{mg} / \mathrm{dL}$, and potassium $3.2 \mathrm{mEq} / \mathrm{L}$. Computed tomography (CT) revealed thickening of the ileal wall in various intestinal loops with proliferation of mesenteric fat and increased vascularization (involving $2 \mathrm{~cm}$ of the terminal ileum and $40 \mathrm{~cm}$ of the proximal ileum), suggestive of Crohn disease. The patient's abdominal pain subsided after 3 days of antibiotics (intravenous ceftriaxone $2 \mathrm{~g}$ once a day and metronidazole $500 \mathrm{mg}$ three times a day) and an ileocolonoscopy revealed aphthous erosion in the ascending colon and edema, erythema, and three ulcers in the terminal ileum with irregular, elevated borders ( $\boldsymbol{\nabla}$ Fig. $\mathbf{1}$ ). Histological examination of the ileal and colonic biopsy specimens showed profuse blast-cell mucosal infiltration ( $\boldsymbol{O} \mathbf{~ F i g . 2 a}$ ). Leder staining and myeloperoxidase immunostaining ( $\boldsymbol{O}$ Fig. $\mathbf{2 b}$ ) confirmed the myeloid nature of the neoplastic cells. A bone marrow biopsy confirmed the diagnosis of acute myeloid leukemia (AML). The French-American-British (FAB) subtype of leukemia in this case was M1. The patient was started on chemotherapy according to the AML-17 protocol with a positive hematological response. She became asymptomatic and a repeat colonoscopy with biopsies showed no signs of disease involvement on histological examination.

Clinically significant extramedullary involvement of the gastrointestinal tract in leukemia is rare [1-5]. Our case is particularly unique because the diagnosis was established following colonoscopy, and serves as an alert for clinicians and endoscopists to consider rare pathologies that may clinically and endoscopically mimic more common diseases in the differential diagnosis.

Endoscopy_UCTN_Code_CCL_1AD_2AD

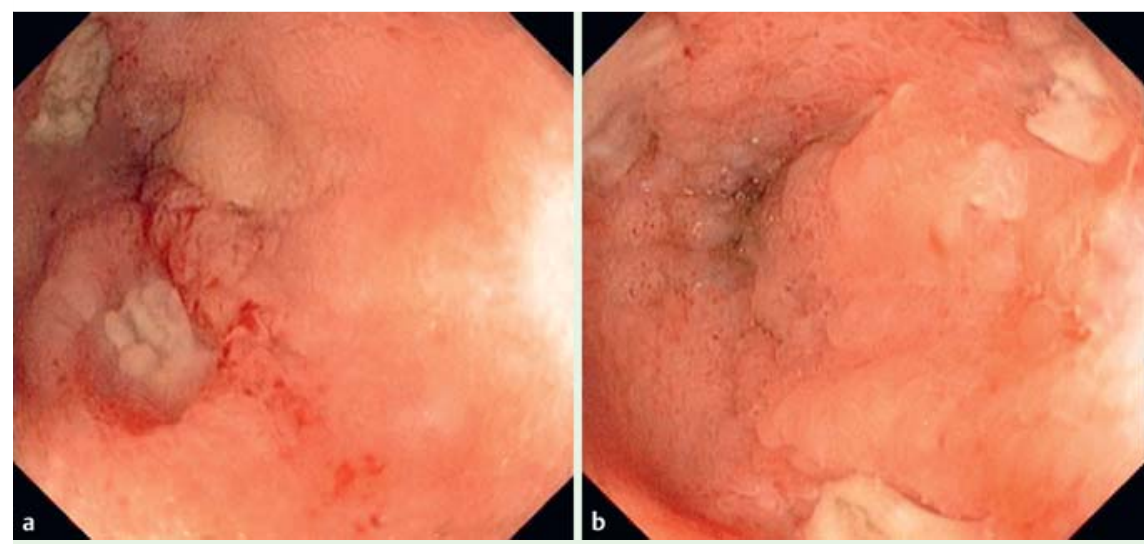

Fig. 1 a, b Colonoscopy showing ileal ulcers with elevated, erythematous borders.

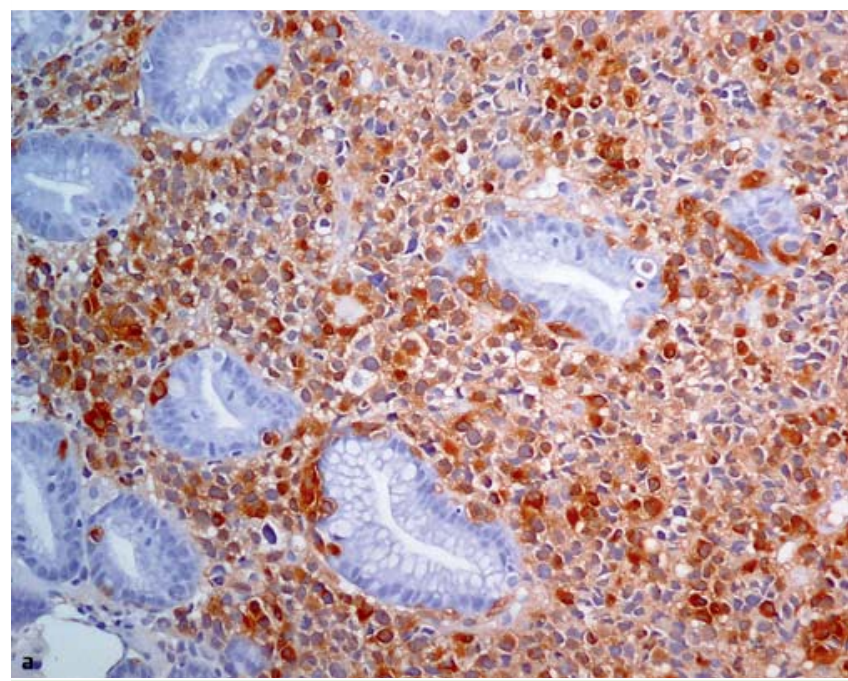

Fig. 2 a Extensive and diffuse infiltration of the mucosa by neoplastic cells (hematoxylin and eosin staining, magnification $\times 200$ ). b Neoplastic cells positive for myeloperoxidase (myeloperoxidase immunostaining, magnification $\times 100$ ).

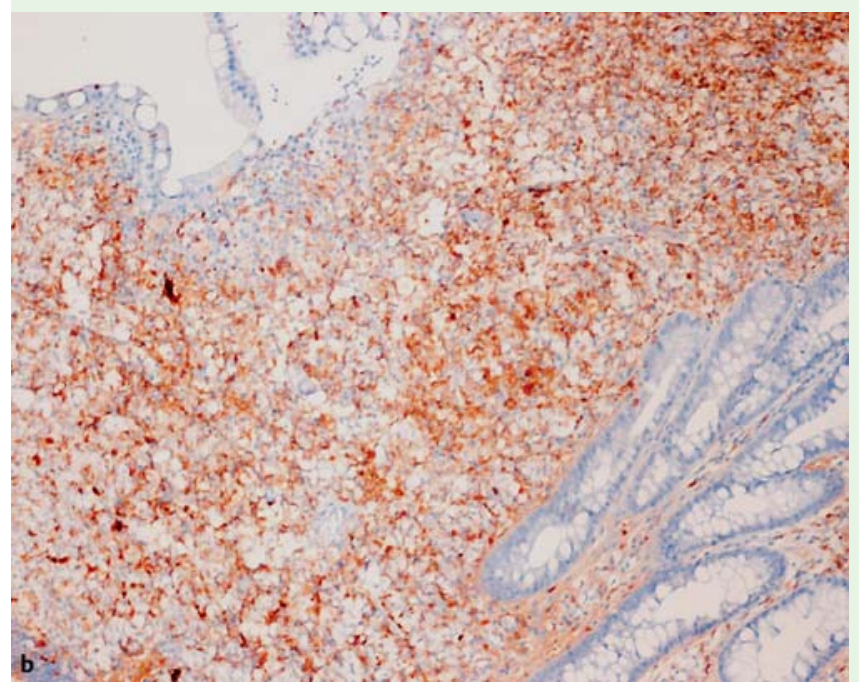

\section{Competing interests: None}




\section{S. Rodrigues ${ }^{1}$, A. Ribeiro ${ }^{1}$, R. Gon- çalves ${ }^{1}$, M. A. Sobrinho-Simões ${ }^{2}$, L. Leite $^{3}$, R. Duarte ${ }^{2}$, E. Fonseca ${ }^{4}$, C. Macedo ${ }^{1}$}

${ }^{1}$ Department of Gastroenterology, Centro Hospitalar de S. João, E.P.E, Portugal

2 Department of Hematology, Centro Hospitalar de S. João, E.P.E, Portugal

${ }^{3}$ Department of Hematology, Instituto Português de Oncologia, Porto, Portugal

${ }^{4}$ Department of Pathology, Centro Hospitalar de S. João, E.P.E, Portugal

\section{References}

1 Ebert EC, Hagspiel KD. Gastrointestinal manifestations of leukemia. J Gastroenterol and Hepatol 2012; 27: 458-463

2 Shepherd NA. Pathological mimics of chronic inflammatory bowel disease. J Clin Pathol 1991; 44: 726-733

3 Barcos M, Lane W, Gomez GA et al. An autopsy study of 1,206 acute and chronic leukemias (1958 to 1982). Cancer 1987; 60: 827-837

4 Prolla JC, Kirsner JB. The gastrointestinal lesions and complications of the leukemias. Ann Intern Med 1964; 61: 1084-1103

5 Antic D, Elezovic I, Bogdanovic A et al. Isolated myeloid sarcoma of the gastrointestinal tract. Intern Med 2010; 49: 853-856

\section{Bibliography}

Dol http://dx.doi.org/

10.1055/s-0032-1326109

Endoscopy 2013; 45: E21-E22

(c) Georg Thieme Verlag KG

Stuttgart · New York

ISSN 0013-726X

\section{Corresponding author}

\section{S. Rodrigues}

Gastroenterology Department, Hospital de São João

Alameda Professor Hernâni Monteiro 4200-319 Porto

Portugal

Fax: +351-225-025766

susanagrodrigues@hotmail.com 